\title{
Road-mapping the business potential of sustainability within the European manufacturing industry
}

\author{
Valkokari, Katri; Valkokari, Pasi; Palomäki, Katariina; Uusitalo, Teuvo; Reunanen, Markku; Macchi, M; \\ Rana, P; Prasanna Liyanage, J
}

\section{Introduction}

Sustainability[1] is definitely a concept of foresight studies. It has been identified as one of the key factors of future competitiveness and business survival since the 1990s (Porter \& van der Linde, 1995; Magretta, 1997; Elkington, 2002; Hart \& Milstein, 2003). Today, sustainability is still driven mainly by the need for regulatory compliance, cost savings through eco-efficiency, corporate social initiatives, and satisfaction of customer demand. Although there already are forerunner companies that are focused on sustainability and that use sustainability as a differentiator, it is not yet broadly considered as a strategic differentiator or creator of competitive advantage. For many companies, however, sustainability remains at the level of PR, expressions in strategies and branding, if it is considered at all. A smooth transition toward sustainability will be possible only with policies that recognise business as a part of the solution and create the right incentives, enabling the European manufacturing industry to adapt and remain competitive globally.

In terms of a future sustainable manufacturing industry and its competitive advantages, current manufacturing models, which are based on the old paradigm of unlimited resources and unlimited capacity for regeneration, need to be updated (Garetti \& Taisch, 2012). Therefore, envisioning of future changes is needed for clarification of industry-, network-, or actor-level specifications for a new, sustainably performing manufacturing industry. In this paper, we utilise a visionary road-mapping approach (configured and tested by Ahlqvist et al. 2010 and 2007) to study the required changes and emerging business opportunities related to sustainable development in the manufacturing industry. We argue that business has much ahead of it if it is to realise the opportunities presented by sustainable production and service business operations. Indeed, to succeed in an ever-changing business environment, manufacturers must be proactive and innovative as well as operationally efficient (Hamel, 2007; Gupta, 2010). For manufacturing companies, development toward sustainability can bring new means of differentiation, and thereby e.g., both operations- and growth-oriented benefits and new business opportunities that support manufacturers in finding their 'blue ocean strategy', a concept originally presented by Kim \& Mauborgne (2005).

Successful influence of future studies can be identified by two alternative hallmarks: i) consciousness has been raised, or ii) foresight is acted upon by the actors involved (Glenn et al., 2001). Accordingly, the overall goal of this paper is twofold. First, the paper targets exploration of the required changes and envisions the key aspects of sustainable manufacturing. Secondly, we approach, roadmaps as multi-layered outlines of possible futures that open perspectives both on overall macro-level impressions and on selected micro-level developments to determine the business potential and the key challenges for a new, sustainable manufacturing industry in order to gain commitment from the businesses, such as network- and company-level actors. The actual research question approaches the issue of sustainable development at several levels: What changes are required within the mechanical engineering sector of the European manufacturing industry to allow utilisation of the business opportunities presented by sustainability?

The paper focuses on competitiveness of the European manufacturing industry, though the changes presented do apply in large measure in the global context also. This paper is structured as follows: In Section 2, we outline the key aspects of sustainable development within the European manufacturing industry, especially in the mechanical engineering sector. We then describe the methodology used in the research (Section 3). In Section 4, we introduce the key transformation fields identified and analysed. Sections 5 and 6 present a road-mapping process and its results related to these key transformation fields. The paper concludes with a summary of the changes needed for a sustainable manufacturing industry, the practical implications, and limitations of the study in Section 7. 


\section{Key aspects of sustainable development in manufacturing}

Environmental, social, and economic dimensions are defined as the 'three pillars' of sustainability, although there are several interpretations of the key aspects of sustainability, as it connects many disciplines and fields. In accordance with this 'triple bottom line', the key challenges that sustainable manufacturing must respond to are as follows:

i) Economic challenges, by creating products effectively and efficiently and creating new services that ensure development and competitiveness through time

ii) Environmental challenges, by promoting minimal use of natural resources (in particular, non-renewable energy) and managing them in the best possible way while reducing environmental impact

iii) Societal challenges, by promoting social development and improved quality of life through renewed quality of wealth and jobs (Jovane et al., 2008)

Manufacturing has a huge impact on all the key challenges of sustainability. Besides a great impact on resources consumption and emissions to the environment - as reported by the International Energy Agency (IEA, 2008), the manufacturing sector is responsible for 33\% of energyconsumption and $38 \%$ of total direct and indirect $\mathrm{CO}_{2}$ emissions - the impact on the economy and society at large are also evident, as manufacturing contributes as much as $20 \%$ of Europe's GDP and $70 \%$ of jobs in Europe are related directly or indirectly to manufacturing (ManuFuture, 2004). Therefore, embedding sustainability in manufacturing is a fundamental lever for contribution. In any case, even understanding of the term 'sustainability' at a relatively basic level varies significantly from one manufacturing firm to the next: some consider sustainability to be mere compliance with environmental legislation, while others see it as involving waste and cost reduction, or reduction of emissions, and still others think of it in terms of workplace and employee rights or community engagement (Bonini et al. 2010).

It is not enough to raise awareness of sustainability or get issues on policymakers' agenda. Real and urgent actions toward sustainability are needed (Riedy, 2009). A shift toward sustainable manufacturing is impossible if the actors within the manufacturing industry itself are not committed to change. In other words, sustainability policies that recognise business as part of the solution and create the right incentives, enabling industry to adapt and remain competitive globally, are required. A recent executive study illustrated that companies' perceptions about sustainability are changing (Bonini, 2011). As in the past, company representatives see the potential for supporting corporate reputation, but recently they have also come to expect operations- and growth-oriented benefits in cutting costs and pursuing opportunities provided by new markets and products (Bonini, 2011).

There is no single, universally applicable way to create value and business opportunities from sustainability. One of the approaches that can generate positive environmental and social value while making a business case for sustainability (Lüdeke-Freund, 2010; Schaltegger et al., 2012; Meier et al., 2010) is product service systems (PSS).. PSS shifts the business focus from designing and selling only physical products, 'to selling a system of products and services', which could have potential sustainability benefits to better internalise the negative environmental and social externalities (such as carbon emissions, resource depletion through use, child and forced labour and waste generation) associated with product manufacture, ownership and use (Goedkoop et al., 1999, Manzini \& Vezzoli, 2002; Tukker \& Tischner, 2006a). Xerox photocopiers and InterfaceFLOR are examples of product-service systems. On the other hand, as asserted by Yunus et al. (2010), 'a social business is a new form of business that can be located somewhere between a profit-maximizing and a non-profit organization'. Social enterprises (e.g., Eight19 Indigo) and social business models (e.g., Grameen Bank) are practical examples of firms generating profit yet not being driven only by economic incentives but emphasising creation of social and environmental benefits. Moreover, engagement with stakeholders (Stubbs \& Cocklin, 2008), such as collaborating with local NGOs to improve integration into the community and understanding of the local culture is an instance of manufacturing firms creating value by developing relationships with broader set of stakeholders in the industrial network. Still, research should be focused on developing additional 
ideal types of sustainable organisations in different contexts (Boutilier, 2005; Sharma \& Starik, 2004). In sustainable development, network- as well as company-specific recipes are needed. For example, knowing where the greatest opportunities for value creation are in an industry or company - and where the risks and barriers lie - can serve as a guide for the development of sustainability strategies.

This paper is aimed at exploring the changes, drivers and obstacles that must be involved if an industry is to capture business opportunities created by sustainability. In this paper, roadmaps are approached as multi-layered outlines of possible futures that open perspectives both on overall macro-level impressions and on selected micro-level developments. Thus, the focus is placed on the European manufacturing industry, with special attention to the mechanical engineering sector (manufacture of basic metals and fabricated metal products, machinery, and equipment). At the macro level, results of road-mapping processes offer insights for policymakers into matters such as how to support sustainable development in the European manufacturing industry. At the same time, at the micro level, roadmaps enable companies and their network actors to visualise the sustainable future concretely and identify their business opportunities related to sustainability. In this paper, the changes are correspondingly examined at three levels:

i) the macro level of the manufacturing industry,

ii) manufacturing networks, and

iii) actors and their business models.

Moreover, the view of manufacturing networks is broadened from vertical supplier-lead producercustomer relationships to horizontal, collaborative relationships of all stakeholders, i.e. the network actors, involved..

\section{Road-mapping as a method for foresight}

Science and technology foresight, including roadmaps, is typically used by national governments to 'support long-range planning for economic and social policy development' (Calof et al., 2006). Therefore, road-mapping has also been used to integrate technology and business planning (Phaal et al., 2001; Farrukh et al., 2003; Saritas \& Aylen, 2010) and for vision-building (De Laat \& McKibbin, 2003). A road-mapping process also helps to facilitate collaboration and visioning among companies within industries, in the formation of joint industry-government research programmes, and in many other venues (MacKenzie et al., 2002). Ahlqvist et al. (2010) point out how the visual emphasis of road-mapping has especially great potential also in business and social studies.

The road-mapping process presented in this paper is adapted from work in the papers of Ahlqvist et al. (2010 and 2007) and Ahola et al. (2010)., In line with Ahlqvist et al. (2010), our intention is not to configure the roadmaps as 'deterministic portrayals of the futures'; i.e., we aim to explore multi-layered outlines of possible futures and do not assume that any of the roadmaps will be realised as they stand. Accordingly, we envision, in the words of Ahola et al. (201) that 'future development is likely to include some elements that are presented in these roadmaps, but there will also be new and surprising elements that obviously could not have been taken into account during their creation'. Therefore, accuracy can be improved by combining forecasts derived via either different methods or different sources of information (Saritas \& Aylen, 2010). Through these viewpoints we have summarised the roadmaps in terms of a framework of the key changes required for sustainable development in the mechanical engineering sector of the European manufacturing industry.

The main research question of our road-mapping process can be formulated as follows: What changes are required within the mechanical engineering sector of the European manufacturing industry to allow utilisation of the business opportunities presented by sustainability? The key question can be divided into sub-questions:

- What are the drivers and obstacles related to a move toward sustainable manufacturing?

- What kinds of temporal sequences do these transformations form? (in view of the present, mid-term, and long-term temporal levels) 
The strength of the road-mapping approach is in the identification of obstacles, as well as solutions for dealing with these obstacles, and in the generation of shared targets (McDowall \& Eames, 2006). Hence, within the road-mapping process, our paper sets out to examine how business opportunities can be linked to sustainability within the manufacturing industry. The target of our concern - the European mechanical engineering sector - has driven our thinking during the process. Furthermore, while the process itself is important for bringing stakeholders together in configuring a shared vision, the final results also provides a valuable description of possible steps, expressed at different temporal levels of roadmaps, against which progress can be compared and measured.

On the whole, our road-mapping process enables envisioning the future at an industry level as well as company-specific scenario-building. Firm-level governance models and practices (Collins et al., 2007; Esslinger, 2011) and supply-chain management (Seuring \& Müller, 2008; Sundarakani et al., 2010) for sustainability are more intensively studied subjects, so a research gap has been identified in the need for a broader view of a sustainable manufacturing industry (Gunasekaran \& Spalanzani, 2012) - i.e., creating a multilevel movement toward sustainability. Such a broader view is achieved in this paper through the three sub-roadmaps for a sustainable manufacturing industry. We conclude by considering the changes needed to the framework for sustainable development in the mechanical engineering sector of European manufacturing industry.

\section{Key transformation levels: The European manufacturing industry, networks, and actors and their business models}

Sustainable development will have quite far-reaching implications for our future. It is a directional process of change by which a system improves through time in a sustainable way. The transformation can occur through either system innovations, as in the emergence of new subsystems that are more sustainable, or managed improvements of the current system. Therefore, given their differing needs (interests), all actors have their own perceptions as to development and improvements, in terms of, for example, what changes bring better, more sustainable circumstances. For us to understand and envision such a development-requiring systemic change, a multilevel approach is needed (Batterman, 2006; Boutilier, 2009; Jovane et al., 2009).

Figure 1 illustrates the different viewpoints at the three levels of change:

(i) European macro level,

(ii) manufacturing network level, and

(iii) the level of actors and their business models.

These levels were identified through PEST analysis (Burt et al., 2006) and a literature review. PEST analysis and its variations illustrate 'Political, Economic, Social, Technological as well as Environmental, Legal, Ethics and demographic' change factors [2]. Batterman (2006) identifies five levels in a 'sustainability hierarchy' that are required for creation of a connecting path between global and individual sustainability activities: global objectives, industry strategy, enterprise targets, specific projects, and individual actions / measured outcomes. On the other hand, in the ManuFuture vision, competitive sustainable manufacturing (CSM) depends on and affects i) manufacturing (e.g., products, services, processes, and business models) and ii) the related policies (e.g., education, research, technological development, and industrial innovation) (Jovane et al., 2009). To highlight the business potential as part of the solution for sustainable development in manufacturing, our approach divides this dimension into network and actor levels. On the whole, three levels of transformation are analysed: the changes drawn at network and actor levels, and the parallel changes occurring at European macro level; these together present a unique picture of the multi-level movement toward sustainability.

[Place Figure 1 here]

As pointed out by Riedy (2009) and by Burt et al. (2006), in works that offer one perspective to future studies, future-studies work can achieve real influence only by translating its findings and recommendations into terms that either connect with existing state imperatives or contribute to the eventual transformation of state imperatives. A multi-layered roadmap allows the evolution within 
each level to be explored, in tandem with the inter-level dependencies, facilitating the integration of key factors (Phaal et al., 2001) - e.g., with sustainable development tied in with manufacturing systems and business models. In other words, the roadmap process bridges industry-level roadmaps to science and research road-mapping, in order to reason the actual changes required and the business potential presented by sustainability. Our study connects sustainable development strongly with the business opportunities of the relevant actors through the discussion in the next three sections, on competitive advantages of the European manufacturing industry (Subsection 4.1), sustainability in manufacturing networks (Subsection 4.2), and actor and business models level (Subsection 4.3).

\subsection{Sustainability as a competitive advantage for European manufacturing}

Sustainability has been identified among the key factors for future competitiveness and business survival since the 1990s (Porter \& van der Linde, 1995; Magretta, 1997; Elkington, 2002; Hart \& Milstein, 2003; Sundarakani et al., 2010; Gunasekaran \& Spalanzani, 2012). From a competitive advantage perspective, it has two major avenues of business impact - first proactive actions to mitigate hidden risks and, second, creation of an initial foundation for capitalisation on potential opportunities in both operating and emerging markets (Liyanage, 2003).

In recent years, the efforts of manufacturing industries to achieve sustainable production have shifted from end-of-pipe solutions to a focus on product life cycles and on integrated environmental strategies and management systems. Furthermore, efforts are increasingly being made to create closed-loop, circular production systems and to adopt new business models, such as a transfer from supplier to service provider or development partner. Because the cost- and benefitsharing in sustainability initiatives - such as ethical trade, a green supply chain, and marketing or reverse logistics - are not clearly defined, many companies are not aware of their business potential (Gunasekaran \& Spalanzani, 2012). While current eco-innovations in manufacturing tend to stress primarily technological advances, organisational or institutional changes have often driven their development and complemented the necessary technological changes. The focus in work on sustainability issues has still, however, been on environmental 'green' issues both in the literature (for a summary, see Seuring \& Müller, 2008; Gunasekaran \& Spalanzani, 2012) and in company practices [3]. Nevertheless, there clearly is a lack of integrated approaches in sustainability frameworks (Aronsson \& Brodin, 2006; Dao et al., 2011; Rana, 2011).

In a traditional manufacturing network, supplier, lead producer (product company or original equipment manufacturer), distributor, and customer can be defined as the most typical roles in the supply chain (Dao et al., 2011) - whereas the industrial product-service systems (PSS) approach includes also societal elements (e.g., government and competitors) among the main actors (Meier et al, 2010). Therefore, it is becoming difficult to categorise companies as manufacturers, lead producers, or product companies as the importance of service business increases (Baines et al., 2009). The lead producers have typically integrated manufacturing, R\&D, and product sales through their value chain. The focus of these companies has been on upstream co-operation with suppliers (Matthyssens et al., 2009; Sundarakani et al., 2010). Since the 1990s, however, this pattern has been changing, and the theoretical discussion too has emphasised the shift from value chains to value networks (Normann \& Ramirez, 1994; Peppard \& Rylander, 2006). The trend among customers, lead producers, and their suppliers seems to be one of increasing collaboration between actors, as in co-creation of value, and a parallel forward transfer in their value chains (Davies, 2004). This means that customers and lead producers outsource manufacturing (give up earlier links in the value chain) and their suppliers try to increase services (add later links in the chain and abandon some earlier ones). Manufacturers are looking at moving closer to their market and thereby trying to relocate either their manufacturing facilities or their distribution centres. Suppliers provide not only raw materials and finished products but also transportation, energy, packaging, design, and recycling services. Therefore, the role of supplier is moving toward that of a development partner (Brax, 2005; Matthyssens et al., 2009). The challenge is to rethink the manufacturing industry as a network of complex and development-oriented relationships.

Still, the state of practice correspondingly reveals different ways of tackling sustainability issues in manufacturing (Jayal et al., 2010), spanning a continuum from highly technology-based to 
highly organisationally-based innovations. 'Lean Manufacturing' is an example of competitive advantage created on the basis of highly organisationally-based innovations aimed at the maximisation of material- and energy-efficiency; reduction in costs, waste, emissions, and pollution are, in fact, the main concern related to sustainability in this case. Another approach is to create value from the exploitation of waste streams, emissions, and discarded products, in order to feed other products or production processes. It is seen, for example, with models such as industrial symbiosis or the reuse, remanufacturing, recycling model. Here, technology-based innovations are important for creation of sustainability, even if the company's capability of leading in the innovation remains a crucial factor. Furthermore, the on-going shift from product-centricity to service-centricity opens new possibilities also for sustainable development within the European manufacturing industry (Tukker \& Tischner, 2006b; Meier et al., 2010; Liu et al., 2012). While the service development requires a new logic of value co-creation with several actors (Vargo \& Lusch, 2008) sustainable development is, therefore, considered from multiple viewpoints. Some authors have even argued that, because of their different business logic, product-service systems would naturally be more sustainable than 'conventional' product-based solutions (Tukker \&Tischner, 2006b; Meier et al., 2010; Lüdeke-Freund, 2010; Schaltegger et al., 2012;).

\subsection{Sustainable value networks within the manufacturing industry}

In the new network economy, the success of a firm depends on its strategic collaboration with other organisations that have an influence on the creation and delivery of its services or products. As pointed out above, in the European manufacturing industry, service-centricity is challenging the companies to broaden their networks and integrate new actors also into sustainable business development. Manufacturing networks can, therefore, be defined as "not only a new type of manufacturing system deriving new strategic capabilities and requiring design tools but also posing new theoretical questions about systems and decision processes' (Shi \& Gregory, 1998). Sustainable value creation in manufacturing networks requires connections between different decisions at different levels in decision hierarchies and to their sustainable impact (Aronsson \& Brodin, 2006)

Radical reorganisation of production and consumption structures too is required for guaranteed sustainability (Collins et al., 2006). Therefore, sustainable development should integrate the upstream and downstream dimensions of networking - Liu et al. (2012) pointed out that integration should reach also the viewpoints of end customers. Furthermore, the link between sustainability and creation of shareholder value should be visible, as pointed out by researchers (Hart \& Milstein 2003; Boutilier, 2009) and practitioners (Magretta, 1997; Bonini, 2011) alike.

Within supply-chain management, a closed-loop model has been identified as one of the key elements of sustainability (Sundarakani et al., 2010). A closed-loop business model includes up-front design of products that can be manufactured by means of materials reclaimed throughout the manufacturing process and at the end of a product's life. Transparency is another key issue in the discussion of supply-chain management for sustainable development (Wognum et al., 2011). The transparency of a supply chain is the degree of shared understanding of and access to product-related information as requested by a supply chain's stakeholders. If appropriately managed, transparency can improve the effectiveness of life-cycle and network management and of continual learning within manufacturing networks.

Other key elements rely on research advances for sustainable value network design and operations. To address this concern, three areas are identified as relevant levers for their potential with respect to sustainability (Garetti \& Taisch, 2012): multi-stage inventory management, aimed at reaching harmonised logistics and optimal supply-chain inventory levels; collaborative planning and management of production and logistics in non-hierarchical networks; and a supply-network design for (re)location plants developed in light of balanced evaluation of the characteristics of products and services, the worker's skills, the transportation time and costs, and the ecological issues. Furthermore, technologies too should be considered as levers: in this connection, technology-based research is fostered, to facilitate cross-enterprise approaches, starting at the supplier, passing through the manufacturing plant, and finally integrating the customers (Cannata et al., 2008). Last but not least, it is important to note that service business development requires 
sharing of knowledge among network actors and could therefore provide more sustainabilityrelated opportunities and potential benefits for all parties in the manufacturing network (Tukker \& Tischner, 2006b; Meier et al., 2010; Liu et al., 2012).A recent article by Esslinger (2011) is one of the few pieces that focus on collaboration with customers in order to reach sustainability. According to his study, a sustainability-driven business model considers a) consumers, as individuals with a complex set of needs, which are only partially satisfied by the consumption of products, and as members of a larger community with complex interdependencies; b) today's underrepresented communities; and c) tomorrow's communities - i.e., the generations of individuals and communities that will follow our own and which depend greatly on today's decisions and behaviours (Esslinger, 2011). A concrete way of exploiting these emerging opportunities is the development and implementation of new, sustainability-driven (industrial) business models.

\subsection{Industrial business models for sustainability}

The change in business logic means that there is now a shift from focusing on short-term harvesting of the fruits of success (profitability and greater shareholder value) to nurturing the roots (building knowledge assets and stakeholder value) for long-term relationships, improved governance, and sustainability (Robinson et al., 2006). According to Liyanage (2003), the specific business benefits from sustainability are gained by reducing costs, creating options, increasing risks, attracting investments, enhancing brand value, reaching new customers, capturing talented employees, influencing product and service innovations, and improving community relations.

The business model of the future will have to place greater emphasis on sustainability in business operations, as well as on the associated impacts of the products or services provided. Sustainability-driven business opportunities in B-to-B markets could be found by achieving higher prices or greater market share through sustainable products, committing new R\&D resources, and responding to regulations (Bonini, 2011). A prerequisite for being able to realise the business opportunities is identification of the externalities and long-term consequences of sustainability, such as environmental impacts, the end-of-life and use phases, and social implications (Evans et al., 2009).

Stubbs and Cocklin (2008) introduced a sustainability business model (SBM) based on two case studies. According to their analysis, the organisations adopting an SBM must i) develop internal structural and cultural capabilities to achieve firm-level sustainability and ii) collaborate with key stakeholders to achieve sustainability for the system of which the organisation is a part (ibid.). Internal practices are more intensively researched (Collins et al., 2007; Esslinger, 2011). As discussed above, studies related to external collaboration within manufacturing networks have focused mainly on the supply-chain side (Seuring \& Müller, 2008; Sundarakani et al., 2010), and a broader view of stakeholders and customers is at least partially absent. In the introduction to this paper, some examples of sustainable business models were presented for exploration of the business potential of sustainability.

\section{A road-mapping process for sustainable manufacturing}

In this section of the paper, we describe the visionary socio-technical roadmap process (Ahlqvist et al., 2007, and 2010; Ahola et al., 2010). The process itself is important for bringing stakeholders together in configuring a shared vision for the sustainability of the mechanical engineering sector in Europe's manufacturing industry. The final multi-level roadmaps also provide a description of possible steps against which progress can be compared and measured. The roadmaps in our case study were made in the 'SustainValue - Sustainable Value Creation in manufacturing networks' project, a three-year research project (2011-2013). The road-mapping process was completed in three phases: mapping of the landscapes of sustainable manufacturing, road-mapping workshops, and roadmap elaboration and finalisation. Figure 2 presents the activities of both the core group and the expert group within these phases. The expert group consisted of both researchers and practitioners, mostly people involved also in the SustainValue project but also including experts 
from outside the project group. Each had several years of experience with the European manufacturing industry and its development challenges (see Table 1). The authors of this paper formed the core group.

\section{[Place Figure 2 and Table 1 here]}

First, the core group mapped and positioned the relevant literature, including existing roadmaps such as ManuFuture (Jovane et al., 2009), Intelligent Manufacturing System, IMS2020 (2009); and ICT for Environmental Sustainability (Ahola et al., 2010). In this phase, the group used PEST analyses also, to identify the drivers, trends, and uncertainties that steer future sustainable development in the European manufacturing industry. The discussion above has summarised this work.

The aim in the expert group's first workshop was to flesh out and brainstorm the key levels of change, setting the vision and objectives of the road-mapping. To allow reflection on the changes that are needed for an industry's development, it is important to know what we want to reach and where we wish to end up. The SustainValue project's main aim served as background for the vision development, and after a process of revision, the long-term vision for sustainability within the European manufacturing industry was crystallised as follows (Palomäki et al., 2011):

New forms of business models and value networks together enable knowledge-based transformation of the manufacturing industry and improve all three dimensions of sustainable value (economic, environmental, and social).

In addition to the vision, the roadmap structure was discussed and developed in the first workshop. In all, 21 people participated to the first workshop and were physically present.

Between the workshops, the core group did quite a lot of back-office work to review the possible development paths at the three key levels of change, in order to prepare for the roadmapping workshop. Naturally, the jointly created vision was an important element guiding this work, - i.e., in envisioning where the manufacturing industry should move in order to achieve sustainability.

Then, a second expert workshop, with 15 participants of whom four took part from remote locations, was held, in June 2011. This workshop had two main tasks: i) identifying the drivers and obstacles and ii) creating roadmap templates. The second expert workshop utilised the Web-based GroupSystem ThinkTank group support system (GSS) tool, consisting of networked computers and dedicated software. This workshop session had a facilitator who managed the software tool. The facilitated collaboration software makes it possible to collect and display participants' responses simultaneously, comment on and organise others' ideas, vote and prioritise, and use the responses to stimulate new ideas and discussion (Porthin \& Rosqvist, 2009). Without it, for example, 'groupthink' or dominance of strong personalities might guide the answers (Phillips \& Phillips, 1993; Piirainen \& Lindqvist, 2010). Furthermore, the workshop-based approach when complemented with the GSS tool allows every participant to contribute, leading to better acceptance of the results. With a computerised GSS, workshops can be better controlled, and all input is fully documented in the system. Consequently, the material can be easily used and analysed after the workshop (Porthin \& Rosqvist, 2009). The GSS tool and the expert workshop were chosen as the data collection method in order to synthesise multiple viewpoints and theoretical approaches and thereby generate rich empirical data. Moreover, this type of virtual work coupled with use of the GSS tool was considered a suitable method at this point in the process, as the participants were already familiar with each other and thus also a more informal and unstructured commenting was possible.

The structure of the second workshop was pre-defined, and the progress of the workshop (i.e., the order of the open questions, prioritisation, and voting) was planned and established in the system prior to the workshop. The first question on which participants entered comments with the GSS tool dealt with the current state of sustainable manufacturing at different roadmap levels (presented in Figure 1). After this, participants were asked to identify and discuss the changes required for realisation of the long-term vision, and the drivers of development toward the vision and obstacles facing it were discussed also. The data (changes, future needs, etc.) collected for the 
three roadmap levels were then grouped into changes that could take place in the short (1-4 years), medium (4-9 years), and long term (about 10 years or more). On the basis of the changes, major sustainability gaps in current business models for European manufacturing industries were identified. All the inputs and commenting were entered in the system and documented.

Thirdly and finally, the second workshop was followed by project core group iterations. Also, two rounds of commenting were organised in summer 2011, and the expert group took part in reviewing and verifying the roadmap templates. This phase's aim was to home in on the change directions in the key areas of transformation and crystallise the connections between the various roadmap elements. The results were summarised and reported upon in September 2011.

\section{Discussion of the results of the road-mapping process}

\subsection{Analysis of drivers and obstacles}

The drivers and obstacles are presented as background to the meta-level roadmap-building (see Table 2). At the second expert workshop, both drivers and obstacles were identified at three key levels of change (European manufacturing industry, network, and actor). In accordance with the further analysis, they were recognised as typically being two sides of the same coin.

Drivers. At the manufacturing-industry level, the most important drivers were related to growing awareness of environmental issues, such as scarcity of natural resources, natural disasters (storms, hurricanes, typhoons, etc.), and environmental changes (for instance, the greenhouse effect). On the other hand, similarities and differences in global legislation and standardisation were identified as both a driver and an obstacle to sustainability. At the value network level, broader system thinking was emphasised as a starting point for sustainable development. Such a vantage point would enable life-cycle approaches and increasing willingness to contribute to the development. At the actor and business model level, the relevance of recognising sustainability as good for the corporate image was highlighted. Then, integrated product-service solutions as well as requirement of stable prices and a constant offer of goods may emerge as sustainability drivers.

Obstacles. At the manufacturing-industry level, the main obstacles were the same as the drivers, being the negative side of the coin (e.g. scarce awareness of environmental changes). Global dispersion of manufacturing operations and European countries' moving of production sites to countries with low production costs and/or growing markets were mentioned in addition. Also at the level of value network, there were many similarities. Still, the absence of ICT solutions that support transparent sharing of efficiency data for all stakeholders during production processes was identified. At the actor and business model level, attitudes and resistance to any change to current methods and business models were highlighted. Similarly, it was pointed out that being the first company to implement sustainable processes might be so costly as to cause unacceptable economic risks.

[Place Table 2 here]

\subsection{Three sub-roadmaps}

The road-mapping process proceeded from definition of the current state of sustainability within the European manufacturing industry to discussion and road-mapping of the changes that are required for a move toward a more sustainable manufacturing industry. From recursive cycling of data and theoretical frames for sustainability in the manufacturing industry, networks, and actors and their business models, the analysis crystallised the views of a group of experts and connected the work with existing theory. The roadmap was split into three sub-roadmaps:

I. Empowerment of stakeholders in the European manufacturing industry, a sub-roadmap dealing with motivation and awareness, and with policymaking in areas such as legislation, fees, and taxes - e.g., the changes that should occur at political and global industry level 
II. Increasing efficiency at network level, a sub-roadmap addressing extension of natural resources, new kinds of co-operation/interfaces, product-service bundles, new ways of working, and efficient use of resources

III. Creating new performance criteria, models, and means of measuring success at actor level, a sub-roadmap that deals with new business models, new kinds of decision-making, and new methods and performance indicators (such as the changes at actor level)

These sub-roadmaps are presented in figures 3, 4, and 5 and are described in more detail in the following sections (6.2.1-6.2.3). In each sub-roadmap, the changes at one of the key transformation levels are highlighted. For better analysis of the transformations, the required changes were categorised again as events that could take place in the short (1-4years), medium (5-9 years), and long term (roughly 10 years or more).

\subsubsection{Empowerment of stakeholders}

The key features of the first sub-roadmap, empowerment of stakeholders, includes the following major elements:

- Need for better awareness and changed behaviour in relation to sustainability issues such as limited resources, the three sustainability pillars, and life-cycle thinking

- Standardisation and legislation that supports sustainable manufacturing

- Improved ways to demonstrate the benefits for customers and companies of developing their actions, products, processes, and services so as to be more sustainable

\section{[Place Figure 3 here]}

As noted at the start of the paper, sustainability is now driven mainly by the need for regulatory compliance, cost savings through eco-efficiency, corporate social initiatives, and satisfaction of customer demand. Accordingly, the key driver of change currently is the business actor's capability of recognising new opportunities facilitated by sustainable development and growing awareness about dimensions of sustainability among different stakeholders. Still, the literature also asserts that when companies are discussing sustainability, often only environmental factors are considered; see, for example, the literature review by Seuring and Müller (2008).

In the medium term, proliferation of standards and certificates is required, so also governmental co-operation is needed if legislation is to be guided toward coherent targets. In other words, macro-level activities - such as joint industry-level initiatives, governmental pressure, or even lower tax burdens for sustainably produced products - were identified as important drivers.

A crucial long-term driver is the change in the behaviour and role of customers, which means, for example, consumers and customers increasingly participating in companies' innovation processes. This has been discovered both in the road-mapping work and in the literature (see, for instance, the discussion related to the concept of open innovation, which was originally presented by Chesbrough 2003). For the companies that were previously providing products, the conventional manner of product development was identified as an obstacle to the co-creation of services with customers. Furthermore, according to the literature, collaboration and joint development through interfaces among various stakeholders (Stubbs \& Cocklin, 2008) and communities (Esslinger, 2011) can provide new opportunities for sustainable value creation. New approaches such as online development communities may be key drivers for sustainable innovations because the communication is very rapid and ideas can be developed efficiently. Still, the sub-roadmap states in accordance with the literature (Saritas \& Aylen, 2010) how creating added value through improved sustainability should imply increasing transparency toward customers, since they have to be convinced (and thus shown) that the often higher prices involved are justified by the measures to improve sustainability.

\subsubsection{Increase in efficiency}

Key features of the second sub-roadmap, increased efficiency, highlight the following elements: 
- Efficiency in production and manufacturing, as well as operational efficiency of products, systems, and services, has to rise

- New types of relationships and collaboration are needed between manufacturers and stakeholders

- The focus of manufacturing has to move from products to new kinds of services and solutions

- Effective ways to deal with the new sustainability requirements of product-service systems have to be implemented in product development processes

\section{[Place Figure 4 here]}

The present key drivers, efficiency in production and a life-cycle orientation, are progressively becoming important, as can be seen also from the increasing amount of literature on life-cycle management and assessments (Andersson et al., 1998; Robèrt, 2000; Rebitzer et al., 2004). The development processes for sustainability-driven business models have to ensure that sustainable life-cycle solutions can be developed and that all phases in the life cycle, from development to disposal, are taken into account. Efficiency in processes and increased sustainability in the use of resources (reduced consumption of resources) are not the only important factors; disposal concepts in development and co-operation between manufacturing-network companies and other stakeholders in the course of the full life cycle are also essential aspects (Rebitzer et al., 2004). When solving the challenge to offer services, such as problems' solutions, to their customers, manufacturing networks have to ask themselves how to realise the greatest individualisation (high solutions variants as an offer) with the highest standardisation in processes and usage of resources. This means a closer relationship with customers and can also create cost benefits.

Modern manufacturing processes have a high degree of division of tasks (Pavitt, 2002; Davies, 2004), and sustainable solutions need to consider a way to integrate different network actors and stakeholders (Aronsson \& Brodin, 2006; Wognum et al., 2010). Both the literature (Davies, 2004; Stubbs \& Cocklin, 2008; Matthyssens et al., 2009) and the 'increasing efficiency' sub-roadmap emphasise that a company in the manufacturing industry has to build new types of dynamic relationship with its partners in the medium term. Within a complex and networked relationship of this kind, the challenge is in how to strengthen the relationship and broaden the perspective - e.g., how to enhance business networks and communities by offering solutions that are exactly what the customer needs.

As pointed out above, the better the solution fits both end users' and customers' needs, the more they can use the solutions in an efficient way that leads to effective tailoring of solutions. Accordingly, there is a need to identify new approaches, ones that allow key partners to work more closely together to optimise sustainability through economies of scale or more easily reach particular resources and activity results. This will allow all key partners in a manufacturing network to be more sustainable and thus more efficient in their energy and resource consumption (Sundarakani et al., 2010). Amongst these changes, more effective ways to deal with sustainability requirements are needed and would be implemented in the product development processes: product-service systems engineering envisions new opportunities to this end (Cavalieri \& Pezzotta, 2012). This would favour offering more tailored product-service bundles for customers' needs, thus supporting transformation of product manufacturers into service providers (Baines et al., 2009), even incorporating products from other manufacturers into their solution offering (Brax, 2005; Miller et al., 2002).

Reduction of waste and emission amounts to a considerable short-term cost if it is an afterthought, so it needs to be embedded in the business model already in the medium term. Producing less waste and therefore using less energy will be less expensive for companies if done properly and with a systemic approach throughout the product life cycle. To reach new sustainability goals, companies have begun to integrate supply-chain actors into their business in order to be more efficient along the whole chain (for example, in the sustainability approaches of Nike, PUMA, and Walmart). Thus suppliers are increasingly becoming system suppliers, as pointed out in the roadmaps and in the literature on manufacturing networks (Matthyssens et al., 2009) and 
thereby it has been argued that the on-going shift from product-centricity to service-centricity creates new possibilities also for sustainable development in the European manufacturing industry (Tukker \& Tischner, 2006b; Meier et al., 2010; Cavalieri \& Pezzotta, 2012; Liu et al., 2012). This means that supplier companies have to consider a more complex supply chain than before. This correlates with the literature, wherein sustainable industrial systems have been considered to be complex sets of development-oriented relationships and decision-making processes (Shi \& Gregory, 1998; Aronsson \& Brodin, 2006; Jovane et al., 2008; Evans et al., 2009). However, the correlation between service-centricity and sustainability has not yet been studied deeply enough. In order for the industry to reach more sustainable manufacturing, changes are needed on multiple levels.

In the medium term, also technological development is essential for achieving significant changes in eco-efficiency, but considerable potential is to be found also in application of existing practices and knowledge to a broader view of the industrial system. In parallel with technologybased research, we should expand the boundaries of the systems in which we operate and integrate elements/variables so as to reach system-wide improvements. Clearly, sustainable development requires both changes in internal structures and external collaboration (Stubbs \& Cocklin, 2008). In the long term, the key driver is a more systemic view of the whole manufacturing network, which can lead to more efficient operation of logistics, manufacturing, engineering, etc. In order to create innovative business solutions, companies will in the future start to work with actors with whom they have not normally worked. This is implemented through different co-operation and collaboration models, such as subcontracting, licensing, partnering, and franchising. These network models present new opportunities for industry to find ways to close loops, save resources, and cut costs. It should be noted, however, that companies are still reluctant to share their expertise and open their business and that broader system-level sustainability thinking is needed.

\subsubsection{Creation of new performance criteria, models, and means of measuring success}

The key features of the third sub-roadmap, for creation of new performance criteria, models, and means of measuring success, address the following points:

- Updating of current business models

- Making sustainability measurable

- Measuring business success through consideration of all sustainability pillars

[Place Figure 5 here]

Although manufacturing networks are adopting new business models such as product-service systems that focus on the performance of the product throughout the whole value network, the third sub-roadmap pointed out that changes related to sustainability in both business models and people are key drivers in the short term. In some cases, development from current business models might be useful for utilisation of the new opportunities provided by sustainability. This development might involve, for example, starting to add information services or decision-making assistance for a product in order to help the customer use the product in a sustainable way, thus leading to increased awareness of sustainability. According to this sub-roadmap and the literature (Evans et al., 2009), updated business models should internalise dimensions of performance that may initially have been externalised. In particular, externalities such as environmental impacts, the end-of-life phase, the use phase, and social implications should be included in evolving perspectives for sustainability.

In the medium term, new, network-level integrated key performance indicators (KPIs) are needed for sustainable development within the manufacturing industry. Transparency must grow in order for calculation of the manufacturer's costs to be more specific and in order to support customers' willingness to pay. At the moment, sustainability is already a performance indicator for some companies but is not in widespread use in B-to-B companies (Seuring \& Muller, 2008). New concepts for visualising life-cycle sustainability for all stakeholders are needed. Transparent measures and KPIs for measuring sustainability have been recently discussed also in the literature (Arena et al., 2009; Wognum et al., 2011). 
In the long term, the main driver for change is the ability to compare settings of different kinds and also balance the three aspects of sustainability: economic, environmental, and social. If performance in these respects is not determined or measured on the same dimension, it will not be possible to deal with trade-offs between these aspects. The literature concurs: more integrated models of sustainability are required (Aronsson \& Brodin, 2006; Stubbs \& Cocklin, 2008; Dao et al., 2011; Rana, 2011).

\subsection{Summary of the sub-roadmaps}

In Table 3, the changes identified in the three sub-roadmaps are summarised to state the conclusions from the work concisely. Although road-mapping tends to focus on a single future (Saritas \& Aylen, 2010), in this paper the sub-roadmaps are utilised as scenarios of 'multiple futures describing multi-layered outlines of possible future trajectories' in order to test the robustness of the proposed roadmap and framework. The road-mapping topic was broad, and the participants had quite different viewpoints, experiences and perceptions in relation to sustainability. That is why the roadmap results remain at a general, higher, level including multiple change items, which were partially overlapping and conflicting. Furthermore, the presence of an external futures researcher could have supported grounding of the road-mapping process.

\section{[Place Table 3 here]}

On the basis of the summary of the sub-roadmaps (see Table 3 , above) the core group configured a framework of the changes required for sustainable development in the European manufacturing industry.

[Place Figure 6 here]

\section{Conclusions}

The purpose of this paper has been to explore the necessary changes and business potential, and thereby envision the key aspects of sustainability, within the European manufacturing industry. For gaining businesses' commitment, it is important to illustrate how sustainabilityoriented thinking as a strategic consideration could provide new business opportunities. More specifically, while most of the current studies have focused on sustainability at supply-side or company level, our study emphasised the need for a broader view of systemic change. We developed roadmaps as multi-layered outlines of possible futures that illustrate the required changes in relation to the existing and evolving theory of sustainability in the manufacturing industry. By connecting industry roadmaps with science and research roadmaps, the study contributed to future studies of sustainability as a solution that incorporates perspectives considering business potential. In a constantly changing world, a new way of doing things will be proposed by setting sustainability as a key criterion for decisions that will create value today and in the future. In view of the three sub-roadmaps for sustainability in the manufacturing industry, it can be stated that wider adoption of system thinking is needed. In increasing numbers, enterprises are taking some steps toward more sustainable manufacturing, but seldom in a holistic manner. Still, there are several actors involved in the co-development of business models for sustainability. Every player in the manufacturing network must be able to understand the difficulties faced and opportunities emerging in the implementation of sustainability. Such network-level sustainability governance mechanisms are not well represented in the current understanding, and the manner in which we conduct research and inform industry is not yet fit for the challenge of creating a sustainable industrial system - for example, new, sustainable manufacturing networks. Thus, the results of the study highlight the need for collateral, horizontal relationships and a jointdevelopment process among stakeholders. 
From a business perspective, this has much to do with ensuring that there are effective supply-side measures coupled with the market conditions that create demand for more sustainable goods and services. Rethinking business models at network level is the core objective, and sustainability is one possible enabler of future competitive advantage within the manufacturing industry. An important key is collaboration - our study points out that new, sustainability-driven business models cannot be implemented in a vacuum; all actors must change together. Collaboration among all network partners with respect to sustainability in the sense of economic, environmental, and social criteria can be enabled and enforced only through development of common approaches and shared transparent KPIs for sustainability within manufacturing networks.

For managers, the core practical implication of the study is related to the identification of how business models could change in the near future for purposes of a more sustainably performing manufacturing industry. When companies are able to be proactive in identifying the changes, they can also be forerunners in the utilisation of new business opportunities provided by sustainability. The roadmaps presented can support the process of change in the direction of sustainability in manufacturing networks. Thus, the results of this study offer networks and their managers new ways of evaluating the level of their sustainable development in terms of the whole network, rather than isolated dimensions. In this way, managers can approach the knowledge-based transition from traditional supply chains toward a sustainable manufacturing industry.

The driver and obstacle analyses and roadmap-building augment also previous European level understanding of, studies of, and policies on the general state of sustainable development in the manufacturing industry. In particular, the importance of sustainability-driven business models was highlighted as an area needing future research also by the policymakers involved. So, as a general outcome the study showed how the road-mapping process itself provided a process of collaborative learning among the actors involved; for example, it helped actors at different levels in the network to gain a better understanding of each other's viewpoints.

This study has evident limitations, which at the same time yield opportunities for further research. To gain a broad perspective on the subject, the authors selected a multidimensional view of sustainability at three levels of change. Qualitative studies in industrial cases could be conducted to test the reliability of the results. Furthermore, the road-mapping process outlined in this paper needs to be worked out further, especially with regard to iterations. The expert work started with collection of the change data, after which the data were 'timed' - i.e., grouped into three periods (into changes that could take place in the short, medium, or long term) and further for formation of the three sub-roadmaps. Though reviewing and iteration rounds within the expert group were carried out also at this point, the roadmaps were iterated to enable reflection not upon the roadmaps as a whole but on the individual change items. A more thorough iteration round could have produced more ideas on, for example, the parts of the roadmap that are now left empty. At the same time, the roadmaps would have benefited from a more profound assessment of the change items in terms of their probability, importance, causes and consequences. In any event, this study targeted recognition of the opportunities and changes on a more general, higher level. Deeper analysis of the change items and their significance is a company- and industry-specific matter and, therefore, should be handled by stakeholders and network actors considering their own context. Also, the results of this study will be complemented in the case-study environments with identification of the changes necessitated at the network-actor level - for example, how their roles and business models should change in order for competitive advantages to be gained through sustainability.

Footnotes:

[1] The most widely quoted definition of sustainability or sustainable development is that of the Brundtland Commission (1987):"Sustainable development is development that meets the needs of the present without compromising the ability of future generations to meet their own needs"

[2] PEST analysis describes a framework of macro-environmental factors used in the environmental scanning component of strategic management. There are several variations on PEST analysis (e.g., SLEP, PESTLE or PESTEL, PESTEC, STEEPLE, and STEEPLED).

]3] Companies operating in consumer markets emphasise sustainability often in their supply chain. For example, in its annual report, PUMA presents the ambitious goals set by the PUMA Sustainability Scorecard for suppliers to reduce their environmental KPIs by $25 \%$ in the years leading up to 2015 . The goals cover water, 
waste, and energy. To assist its suppliers, PUMA has initiated programmes with third-party service providers and arranged capacity-building work in the countries from which sourcing is done. Similarly, Nike points out its vision of a closed-loop business model that includes the up-front design of products that can be manufactured with materials reclaimed throughout the manufacturing process and at the end of a product's life. On the other hand, companies in engineering sectors offering B-to-B solutions move toward sustainability also through lifecycle services. For example, ABB has recently launched a new service platform offering scalable solutions, which range from global consulting to long-term partnership to support operations and maintenance. The strategy behind the platform, particularly addressed by long-term agreements, is to coach clients in reaching reliability and efficiency through their own assets' life cycle, thus guaranteeing plant productivity together with balanced energy consumption.

\section{References}

Ahlqvist, T., Bäck, A., Heinonen, S., \& Halonen, M. (2010). Road-mapping the societal transformation potential of social media, Foresight, Vol. 12, No. 5, pp. 3-26.

Ahlqvist, T., Carlsen, H., Iversen, J. \& Kristiansen, E. (2007). Nordic ICT Foresight.

Futures of the ICT environment and applications on the Nordic level. VTT Publications 653,

Espoo, Finland. Ahola, J., Ahlqvist, T., Ermes, M., Myllyoja, J., \& Savola, J. (2010). ICT for environmental sustainability: Green ICT roadmap. VTT Research Notes 2532. Helsinki: Edita Prima Oy.

Andersson, K., Eide, M.H., Lundqvist, U., \& Mattson, B. (1998). The feasibility of including sustainability in LCA for product development, Journal of Cleaner Production, Vol. 6, No. 3, pp. 289-298.

Arena, M., Duque Ciceri, N., Terzi, S., Bengo, I., Azzone, G., \& Garetti M. (2009). A state-of-theart of industrial sustainability: Definitions, tools, metrics, International Journal Product Lifecycle Management, Vol. 4, Nos. 1/2/3, pp. 207-251.

Aronsson, H. \& Brodin, M. (2006). The environmental impact of changing logistics structures, International Journal of Logistics Management, Vol. 17, No. 3, pp. 394-415.

Batterman, R.J. (2006). Sustainability: The next chapter, Chemical Engineering Science, Vol. 61, pp. 4188-4193.

Baines T.S., Lightfoot H.W., Benedettini O., \& Kay, J.M., (2009). The servitization of manufacturing: A review of literature and reflection on future challenges, Journal of Manufacturing Technology Management, Vol. 20,No. 5, pp. 547-567.

Bonini, S., Gorner, S., \& Jones, A. (2010). How companies manage sustainability, McKinsey Global Survey results (available at: http://www.businessinsociety.eu/resources/3930).

Bonini, S. (2011). The business of sustainability, McKinsey Global Survey results (available at: http://download.mckinseyquarterly.com/the business of sustainability.pdf).

Boutilier, R. (2005). Views of sustainable development: A typology of stakeholders' conflicting perspectives. In Starik, M., Sharma, S., Egri, C., \& Bunch, R. (eds), New Horizons in Research on Sustainable Organisations: Emerging Ideas, Approaches and Tools for Practitioners and Researchers. Sheffield, UK: Greenleaf, pp. 19-37.

Boutilier, R. (2009). Stakeholder Politics: Social Capital, Sustainable Development, and the Corporation. Greenleaf Publishing Ltd.

Brax, S. (2005). A manufacturer becoming service provider - challenges and a paradox, Managing Service Quality, Vol. 15, No. 2, pp. 142-155.

Burt, G., Wright, R., Bradfield, R., Cairns, G., \& van der Hejden, K. (2006). The Role of Scenario Planning in Exploring the Environment in View of the Limitations of PEST and its derivatives, International Studies of Management and Organisations, Vol. 36, No. 3, pp. 50-76.

Calof, J., Tanguay, D., \& Spring, L. (2006). Addressing Canada's Foresight Capacity: A Report to the National Science Advisor. Ottawa: Science and Technology Foresight Directorate, Office of the National Science Advisor, Government of Canada, 15 September.

Cannata, A., Gerosa, M., \& Taisch, M. (2008). A technology roadmap on SOA for smart embedded devices: Towards intelligent systems in manufacturing, Proceedings of the IEEE International Conference on Industrial Engineering and Engineering Management (IEEM 2008), pp. 762-767. Cavalieri, S. \& Pezzotta, G. (2012). Product-service systems engineering: State of the art and research challenges, Computers in Industry, Vol. 63, No. 4, pp. 278-288. 
Chesbrough, H. (2003). Open Innovation. Boston: Harvard Business School Press.

Collins, E., Lawrence, S., Pavlovich, K., \& Ryan, C. (2007). Business networks and the uptake of sustainability practices: The case of New Zealand, Journal of Cleaner Production, Vol. 15, No. 8, pp. $729-740$.

Dao, V., Langella, I., \& Carbo, J. (2011). From green to sustainability: Information technology and an integrated sustainability framework, Journal of Strategic Information Systems, Vol. 20, No. 1, pp. $63-79$.

Davies, A. (2004). Moving base into high-value integrated solutions: A value stream approach, Industrial and Corporate Change, Vol. 13, No. 5, pp. 727-756.

De Laat, B. \& McKibbin, S. (2003). The Effectiveness of Technology Road Mapping - Building a Strategic Vision. Paris: Dutch Ministry of Economic Affairs, Research Management Association, Working Group Report No. 52.

Elkington, J. (2002). Cannibals with Forks. Oxford, UK: Capstone Publishing Ltd.

Esslinger, H. (2011). Sustainable design: Beyond the innovation-driven business model, Journal of Product Innovation Management, Vol. 28, No. 3, pp. 401-404.

Evans, S., Bergendahl, M.N., Gregory, M., \& Ryan, C. (2009). Towards a sustainable industrial system - with recommendations for education, research, industry and policy. Cambridge, UK: University of Cambridge Institute for Manufacturing, Department of Engineering (available at: http://www.ifm.eng.cam.ac.uk/sis/industrial sustainability report.pdf).

Farrukh, C., Phaal, R.D., \& Probert, R. (2003). Technology road-mapping: Linking technology resources into business planning, International Journal of Technology Management, Vol. 26, pp. $12-19$.

Garetti, M. \& Taisch, M. (2012). Sustainable manufacturing: trends and research challenges, Production Planning \& Control, Vol. 23, pp. 83-104.

Glenn, J.C., Gordon, T.J., \& Dator, J. (2001). Closing the deal: How to make organizations act on futures research, Foresight, Vol. 3, No. 3, pp. 177-189.

Goedkoop, M.J., van Halen, J.G., te Riele, H. \& Rommens, P.J.M. (1999). Product service systems, ecological and economic basics, Ed Vrom EZ, The Hague.

Gunasekaran, A. \& Spalanzani,A. (2012). Sustainability of manufacturing and services:

Investigations for research and applications. International Journal of Production Economics, Vol. 140,No. 1, pp. 35-47.

Gupta, V.K. (2010). Flexible strategic framework for managing forces of continuity and change study of outbound automotive supply chain management in India, International Journal of Value Chain Management, Vol. 4, No. 4, pp. 365-379.

Hamel, G. (2007). Future of Management. Harvard Business School Press Books.

Hart, L. \& Milstein, M.B. (2003). Creating sustainable value, Academy of Management Executive, Vol. 17, No. 2, pp. 56-67.

IEA (2008). Worldwide Trends in Energy Use and Efficiency. Key Insights from IEA Indicator Analysis. Paris: International Energy Agency (IEA).

IMS2020 (2009). Supporting Global Research for IMS2020 Vision. Intelligent Manufacturing Systems (IMS) Program, funded by the European Commission (available at: www.ims2020.net). Jayal, A.D., Badurdeen, F., Dillon, O.W., \& Jawahir, I.S. (2010). Sustainable manufacturing: Modelling and optimization challenges at the product, process and system levels, CIRP Journal of Manufacturing Science and Technology, Vol. 2, pp. 144-152.

Jovane, F., Westkämper, E., \& Williams, D. (2009). The ManuFuture Road-Towards Competitive and Sustainable High-Adding-Value Manufacturing. Springer.

Jovane, F., Yoshikawa, H., Alting, L., Boer, C., Westkamper, E., Williams, D., Tseng, M., Seliger, G., \& Paci, A. (2008). The incoming global technological and industrial revolution towards competitive sustainable manufacturing, CIRP Annals - Manufacturing Technology, Vol. 57, No. 2, pp. 641-659.

Kim, W.C. \& Mauborgne, R. (2005). Blue Ocean Strategy. Harvard Business School Press. Liu, S., Kasturiratne, D., \& Moizer, J. (2012) A hub-and-spoke model for multi-dimensional integration of green marketing and sustainable supply chain management, Industrial Marketing Management, Vol. 41, No. 4, pp. 581-588. 
Liyanage, J.P. (2003). Operations and Maintenance Performance in Oil \& Gas Production Assets: Theoretical Architecture and Capital Value Theory in Perspective, PhD thesis, Norway: Norwegian University of Science and Technology.

Lüdeke-Freund, F. (2010). Towards a conceptual framework of business models for sustainability, Proceedings of the ERSCP-EMU Conference, Delft, The Netherlands, pp. 1-28.

MacKenzie, D.R., Donald, S., Harrington, M., Heil, R., Helms, T.J., \& Lund, D. (2002). Methods in Science Roadmapping: How to Plan Research Priorities. University of Maryland (available at: http://www.escop.msstate.edu/archive/roadmap-methods.doc).

MANUFUTURE (2004). A vision for 2020: Assuring the future of manufacturing in Europe. (available at: http://www.manufuture.org)

McDowall, W. \& Eames, M. (2006). Forecasts, scenarios, visions, backcasts and roadmaps to the hydrogen economy: A review of the hydrogen futures literature, Energy Policy, Vol. 34, No. 11, pp. $1236-1250$.

Magretta, J. (1997). Growth through global sustainability, An interview with Monsanto's CEO, Robert B. Shapiro, Harvard Business Review, Vol. 75, No. 1, pp. 78-88.

Magretta, J. (2002). Why business models matter, Harvard Business Review, Vol. 80, No. 5, pp. 86-92.

Matthyssens, P., Vandenbempt, K., \& Weyns, S. (2009). Transitioning and co-evolving to upgrade value offerings: A competence-based marketing view, Industrial Marketing Management, Vol. 38, No. 5, pp. 504-512.

Manzini, E \& Vezzoli, C, (2002). Product-Service Systems and Sustainability, Paris.

Meier, H., Roy, R., \& Seliger, G. (2010). Industrial product-service systems - IPS2, CIRP Annals Manufacturing Technology, Vol. 59, No. 2, pp. 607-627.

Miller, D., Hope, Q., Eisenstat, R., Foote, N., \& Galbraith, J. (2002). The problem of solutions:

Balancing clients and capabilities, Business Horizons, Vol. 45, No. 2, pp. 3-12.

Normann, R. \& Ramirez, R. (1994). Designing Interactive Strategy: From the Value Chain to the Value Constellation. Chichester, UK: John Wiley \& Sons.

Palomäki, K., Reunanen, M., Valkokari, P., \& Valkokari, K. (2011). Sustainability Gaps and Stakeholder Requirements: Internal Research Report of [the] SustainValue project (D1.1.). Pavitt, K. (2002). System integrators as 'post-industrial' firms? DRUID Summer Conference in Industrial Dynamics of the New and Old Economy, SPRU: Science and Technology Policy Research.

Peppard, J. \& Rylander, A. (2006). From value chain to value network: Insights for mobile operators, European Management Journal, Vol. 24, No. 2-3, pp. 128-141.

Phaal, R., Farrukh, C., \& Probert, D. (2001). Technology Road-mapping: Linking Technology Resources to Business Objectives. Cambridge, UK: University of Cambridge (available at: http://www.ifm.eng.cam.ac.uk/ctm/publications/tplan/trm white paper.pdf).

Phillips, L.D. \& Phillips, M.C. (1993). Facilitated work groups: Theory and practice, Journal of the Operational Research Society, Vol. 44, No. 6 (Interface between OR and the Social Sciences, June), pp. 533-549.

Piirainen, K. \& Lindqvist, A. (2010). Enhancing business and technology foresight with electronically mediated scenario process, Foresight, Vol. 12, No. 2, pp. 16-37.

Porter, M.E. \& van der Linde, C. (1995). Green and competitive: An underlying logic links the environment, resource productivity, innovation, and competitiveness, Harvard Business Review, Vol. 73, No. 5, pp. 120-129.

Porthin, M. \& Rosqvist, T. (2009). Computerised risk analysis workshops. In: Rouhiainen, V. (ed.), Scientific Activities in Safety \& Security 2009. Espoo, Finland: VTT.

Rana, P. (2011). Exploration of Corporate Social Responsibility (CSR) in Food Manufacturing Companies. PhD thesis. Cambridge, UK: University of Cambridge.

Rebitzer, G., Ekvall, T., Frischknecht, R., Hunkeler, D., Norris, G., Rydberg, T., Schmidt, W.-P., Suh, S., Weidema, B.P., \& Pennington, D.W. (2004). Life cycle assessment - part 1: Framework, goal and scope definition, inventory analysis, and applications, Environment International, Vol. 30, No. 5, pp. 701-720.

Riedy, C. (2009). The influence of futures work on public policy and sustainability, Foresight, Vol. 11 , No. 5, pp. 40-56. 
Robèrt, K.-H. (2000). Tools and concepts for sustainable development, how do they relate to a general framework for sustainable development, and to each other? Journal of Cleaner Production, Vol. 8, No. 3, pp. 243-254.

Robinson, H.S., Anumba, C.J., Carrillo, P.M., \& Al-Ghassani, A.M. (2006). STEPS: A knowledge management maturity roadmap for corporate sustainability, Business Process Management Journal, Vol. 12, No. 6, pp. 793-808.

Saritas, O. \& Aylen, J. (2010). Using scenarios for roadmapping: The case of clean production, Technological Forecasting and Social Change, Vol. 77, No. 7, pp. 1061-1075.

Schaltegger, S., Lüdeke-Freund, F. \& Hansen, E., (2012). Business cases for sustainability: the role of business model innovation for corporate sustainability. International Journal of Innovation and Sustainable Development, Vol. 6, No. 2, (in press).

Seuring, S. \& Müller, M. (2008). From a literature review to a conceptual framework for sustainable supply chain management, Journal of Cleaner Production, Vol. 16, No. 15, pp. 1699-1710.

Sharma, S. \& Starik, M. (2004). Stakeholders, the environment and society: Multiple perspectives, emerging consensus. In S. Sharma \& M. Starik (eds), Stakeholders, the Environment, and Society. Cheltenham, UK: Edward Elgar, pp. 1-22.

Shi, Y. \& Gregory, M. (1998). International manufacturing networks - to develop global competitive capabilities, Journal of Operation Management, Vol. 16, No. 2-3, pp. 195-214.

Stubbs, W. \& Cocklin, C. (2008). Conceptualizing a 'sustainability business model', Organization \& Environment, Vol. 21, No. 2, pp. 103-127.

Sundarakani, B., de Souza, R., Goh, M., \& van Over, D. (2010). A sustainable green supply chain for globally integrated networks. In Wang, K. \& Koh, L.S.C. (eds), Enterprise Networks and Logistics for Agile Manufacturing. London: Springer-Verlag, pp. 191-206.

Tukker, A. \& Tischner, U. (2006a). Product-services as a research field: Past, present and future. Reflections from a decade of research, Journal of Cleaner Production, Vol. 14, No. 17, pp.15521556.

Tukker, A. \& Tischner, U. (2006b). New Business for Old Europe Product-Service Development, Competitiveness and Sustainability, Sheffield, UK: Greenleaf Publishing.

United Nations General Assembly (1987). Report of the World Commission on Environment and Development: Our Common Future; Transmitted to the General Assembly As an Annex to document A/42/427 - Development and International Co-operation: Environment; Our Common Future, Chapter 2: Towards Sustainable Development; Paragraph 1. United Nations General Assembly, 20 March (available at: http://www.un-documents.net/ocf-02.htm).

Vargo, S.-L. \& Lusch, R.F. (2008). Service-dominant logic: Continuing the evolution, Journal of the Academy of Marketing Science, Vol. 36, No.1, pp. 1-10.

Wognum, P.M., Bremmers, H., Trienekens, J.H., van der Vorst, J.G.A.J., \& Bloemhof, J.M. (2011). Systems for sustainability and transparency of food supply chains - current status and challenges, Advanced Engineering Informatics, Vol. 25, No. 1, pp. 65-76.

Yunus, M., Moingeon, B., \& Lehmann-Ortega, L. (2010). Building social business models: Lessons from the Grameen experience, Long Range Planning, Vol. 43, No. 2-3, pp. 308-325. 


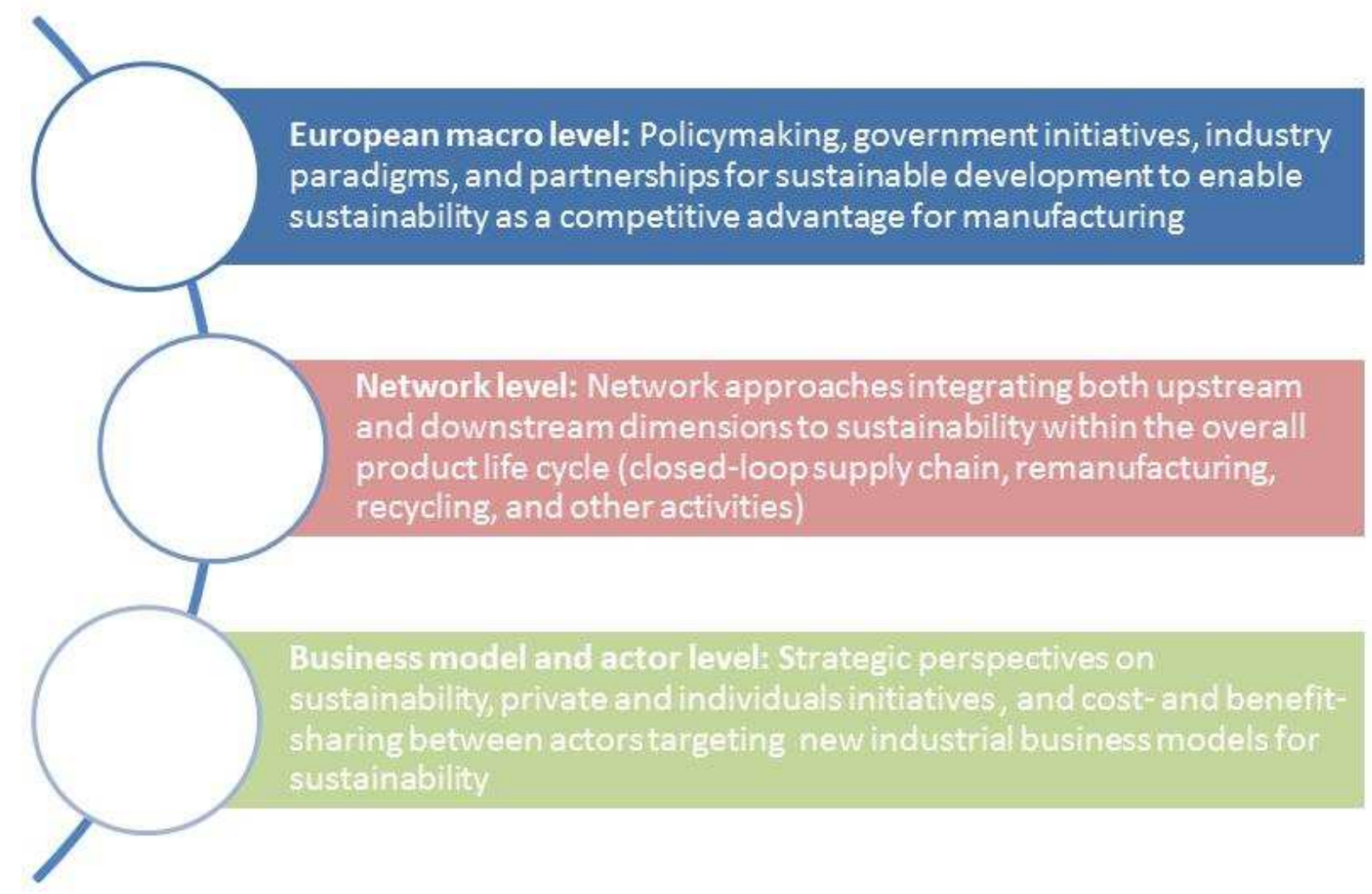

Figure 1: The three levels of change 
PHASE I

Mapping the landscapes of sustainable manufacturing industry
PHASE ॥

Road-mapping workshop
PHASE III

Road-map elaboration and finalization

Presentation of results

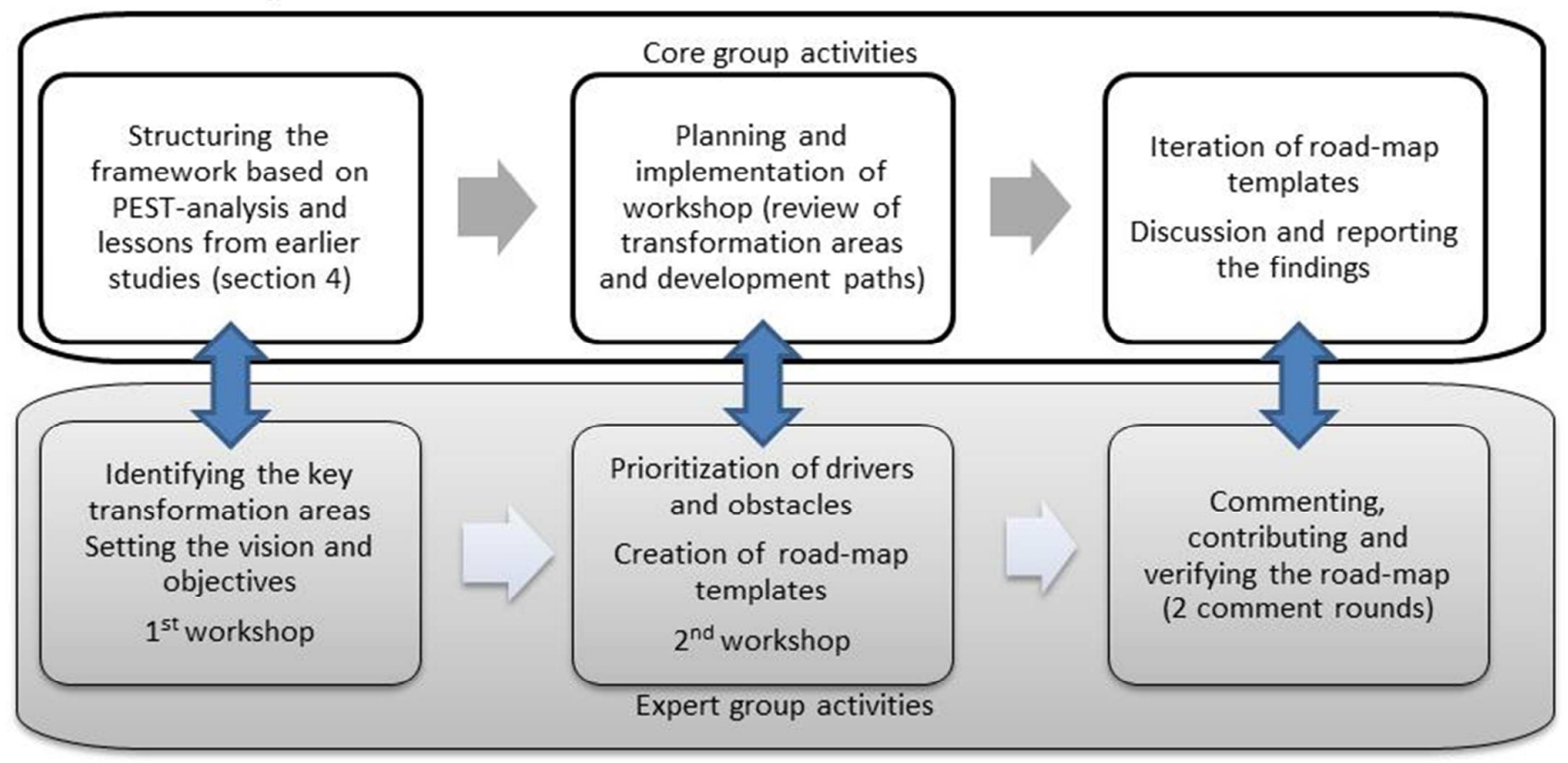

Figure 2: The road-mapping process 


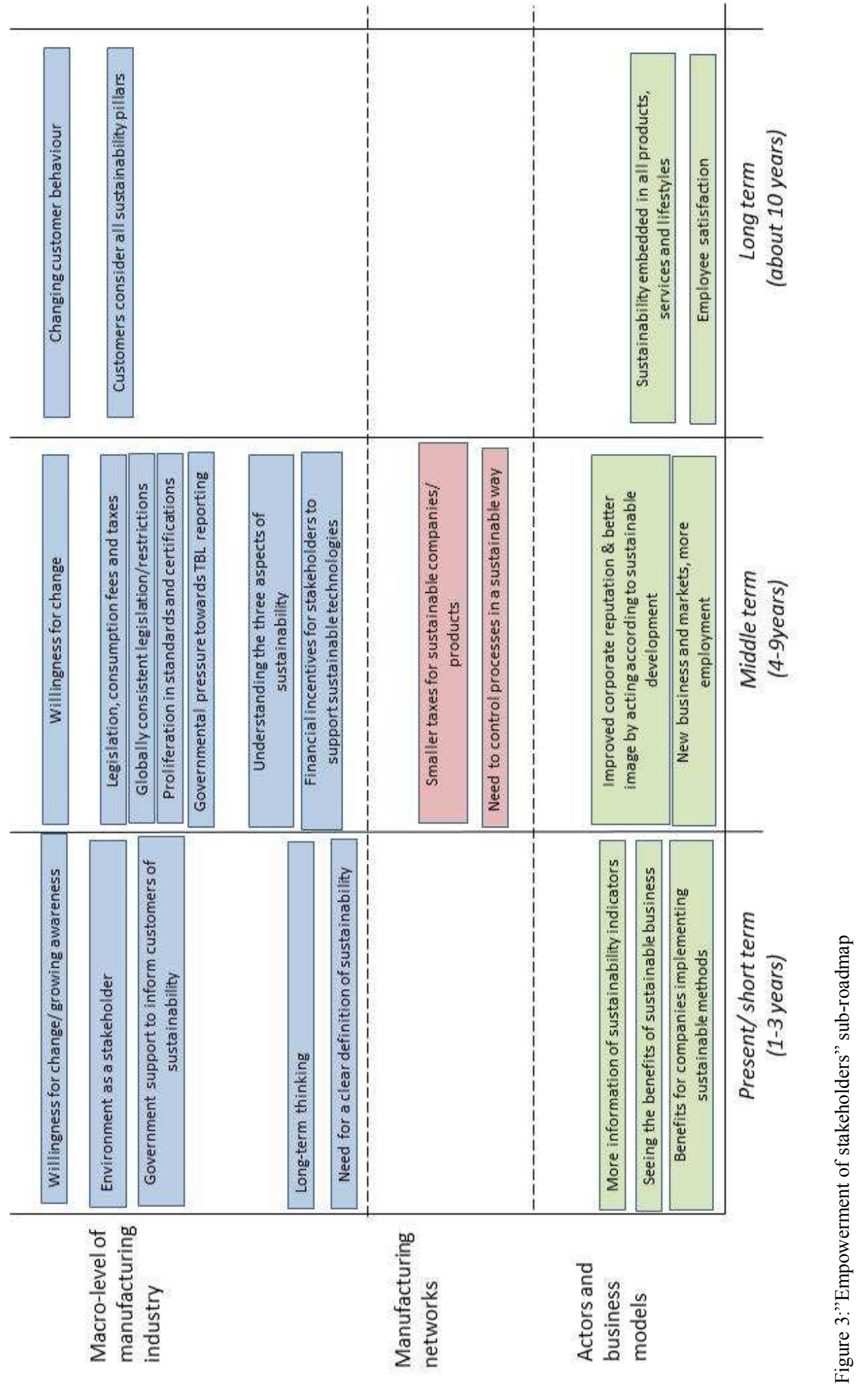




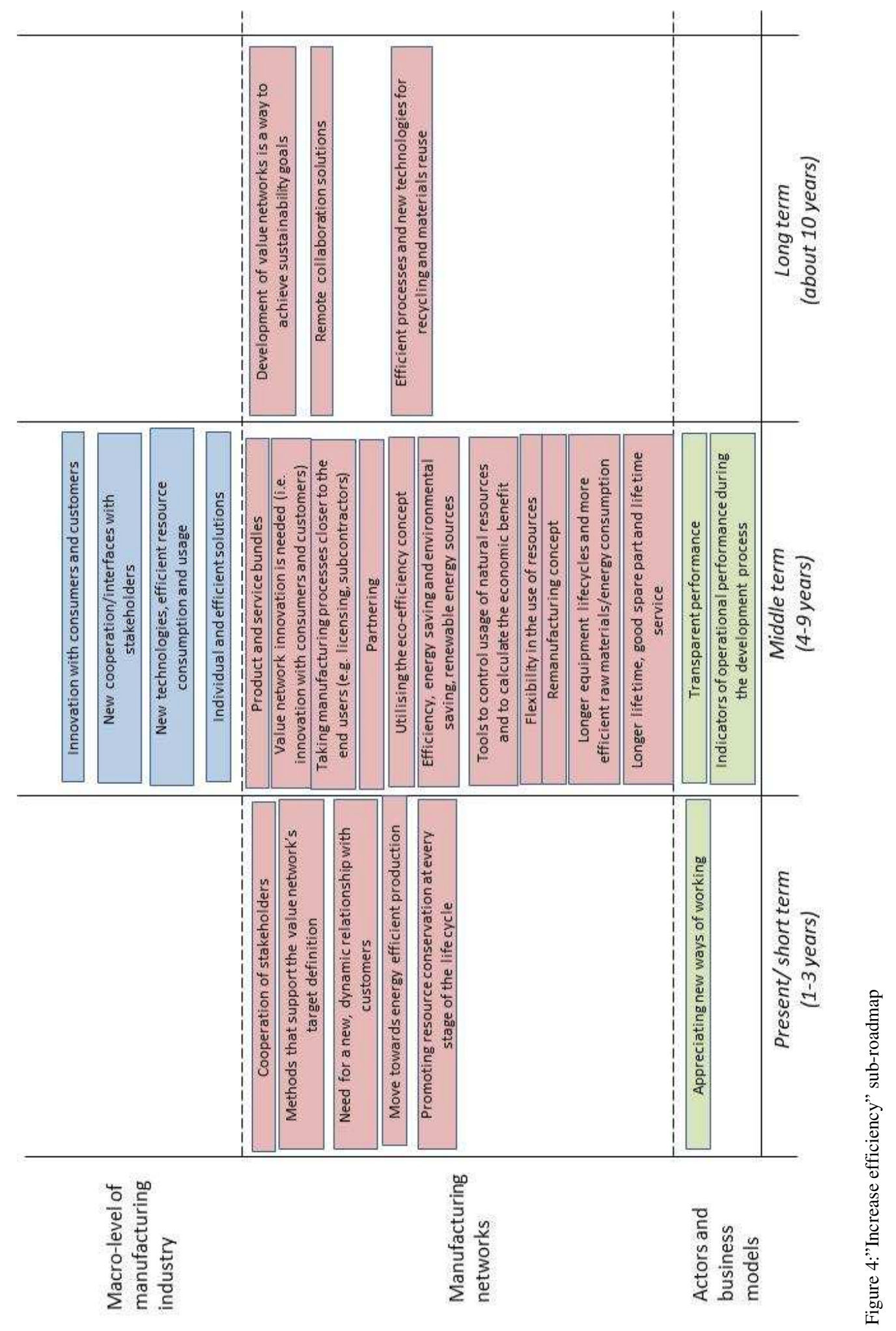




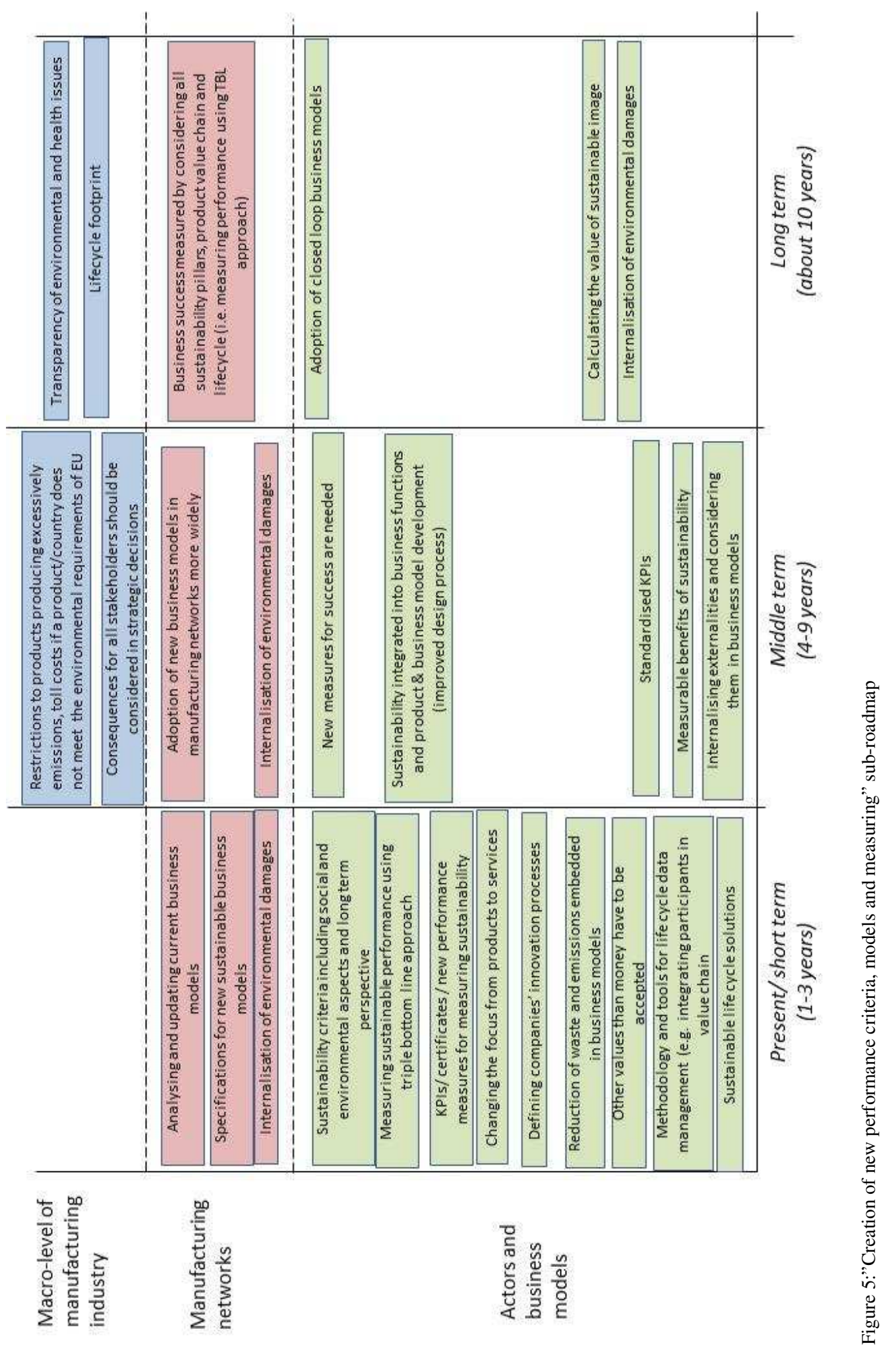




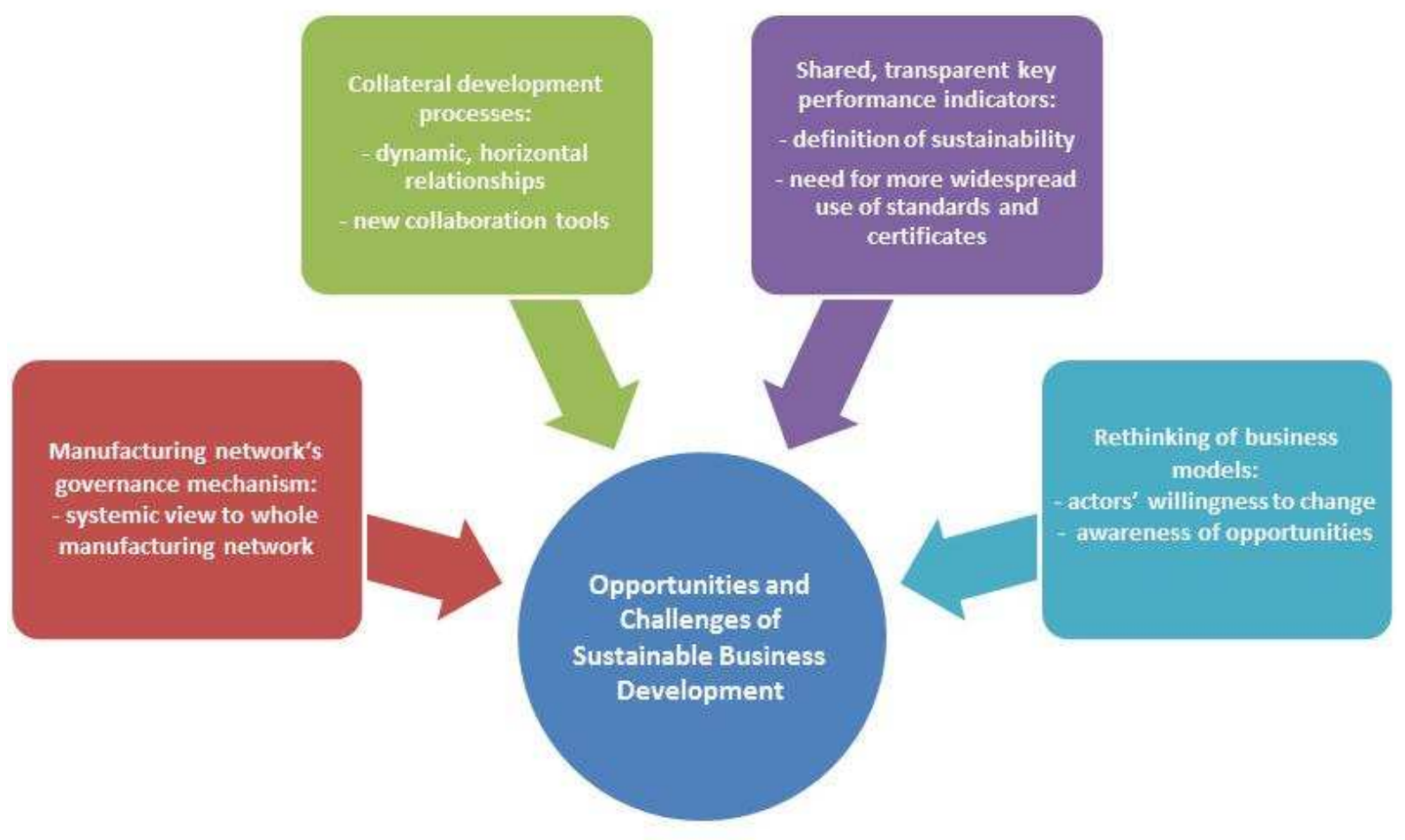

Figure 6: Framework of the changes required for a sustainable manufacturing industry 
Table 1: Competence areas of the expert group

\begin{tabular}{|c|c|c|c|c|c|c|c|}
\hline Experts & $\begin{array}{l}\text { Sustain- } \\
\text { ability }\end{array}$ & $\begin{array}{c}\text { European } \\
\text { manu- } \\
\text { facturing } \\
\text { industry }\end{array}$ & $\begin{array}{l}\text { Manu- } \\
\text { facturing } \\
\text { networks }\end{array}$ & $\begin{array}{c}\text { Industry } \\
\text { needs and } \\
\text { business } \\
\text { models }\end{array}$ & $\begin{array}{c}\text { Workshop } \\
1\end{array}$ & $\begin{array}{c}\text { Workshop } \\
2\end{array}$ & $\begin{array}{c}\text { Comment } \\
\text { rounds }\end{array}$ \\
\hline Policy maker 1 & $x$ & $x$ & & $x$ & $x$ & & $x$ \\
\hline Policy maker 2 & & $\mathbf{x}$ & & & $\mathbf{x}$ & & $\mathbf{x}$ \\
\hline Policy maker 3 & & $\mathbf{x}$ & & & $\mathbf{x}$ & $\mathbf{x}$ & $\mathbf{x}$ \\
\hline Industry partner 1 & & $\mathbf{x}$ & & $x$ & $x$ & & $x$ \\
\hline Industry partner 2 & $\mathbf{x}$ & $\mathbf{x}$ & & $x$ & $\mathbf{x}$ & $\mathbf{x}$ & $\mathbf{x}$ \\
\hline Industry partner 3 & $x$ & & & $x$ & $\mathbf{x}$ & $x$ & $x$ \\
\hline Industry partner 4 & & $\mathbf{x}$ & & $\mathbf{x}$ & $x$ & $\mathbf{x}$ & $x$ \\
\hline Researcher 1 & $\mathbf{x}$ & $\mathbf{x}$ & $\mathbf{x}$ & & $\mathbf{x}$ & & $\mathbf{x}$ \\
\hline Researcher 2 & & $x$ & & & & $\mathbf{x}$ & $x$ \\
\hline Researcher 3 & $x$ & $x$ & & $x$ & & $x$ & $x$ \\
\hline Researcher 4 & & $\mathbf{x}$ & $\mathbf{x}$ & & $\mathbf{x}$ & & $\mathbf{x}$ \\
\hline Researcher 5 & $x$ & & & $\mathbf{x}$ & & $x$ & $x$ \\
\hline Researcher 6 & $\mathbf{x}$ & $\mathbf{x}$ & & $\mathbf{x}$ & $\mathbf{x}$ & & $\mathbf{x}$ \\
\hline Researcher 7 & $\mathbf{x}$ & $\mathbf{x}$ & $x$ & $x$ & $x$ & & $x$ \\
\hline Researcher 8 & $x$ & & $x$ & $x$ & $x$ & $x$ & $x$ \\
\hline Researcher 9 & & & $x$ & $x$ & $x$ & & $x$ \\
\hline Researcher 10 & & $x$ & & & $x$ & & $x$ \\
\hline Researcher 11 & $x$ & $x$ & & $x$ & $x$ & $x$ & $x$ \\
\hline Researcher 12 & $x$ & $x$ & & & & $x$ & $x$ \\
\hline Researcher 13 & $x$ & $x$ & & $x$ & $x$ & $x$ & $x$ \\
\hline Researcher 14 & & $\mathbf{x}$ & & $\mathbf{x}$ & $x$ & $x$ & $x$ \\
\hline Researcher 15 & & & $x$ & $x$ & $x$ & $x$ & $x$ \\
\hline Researcher 16 & $x$ & $x$ & & $x$ & $x$ & $x$ & $x$ \\
\hline Researcher 17 & $\mathbf{x}$ & $\mathbf{x}$ & $\mathbf{x}$ & $\mathbf{x}$ & $\mathbf{x}$ & & $\mathbf{x}$ \\
\hline Researcher 18 & $x$ & $x$ & & $x$ & $x$ & $x$ & $x$ \\
\hline Together & & & & & 21 & 15 & 25 \\
\hline
\end{tabular}




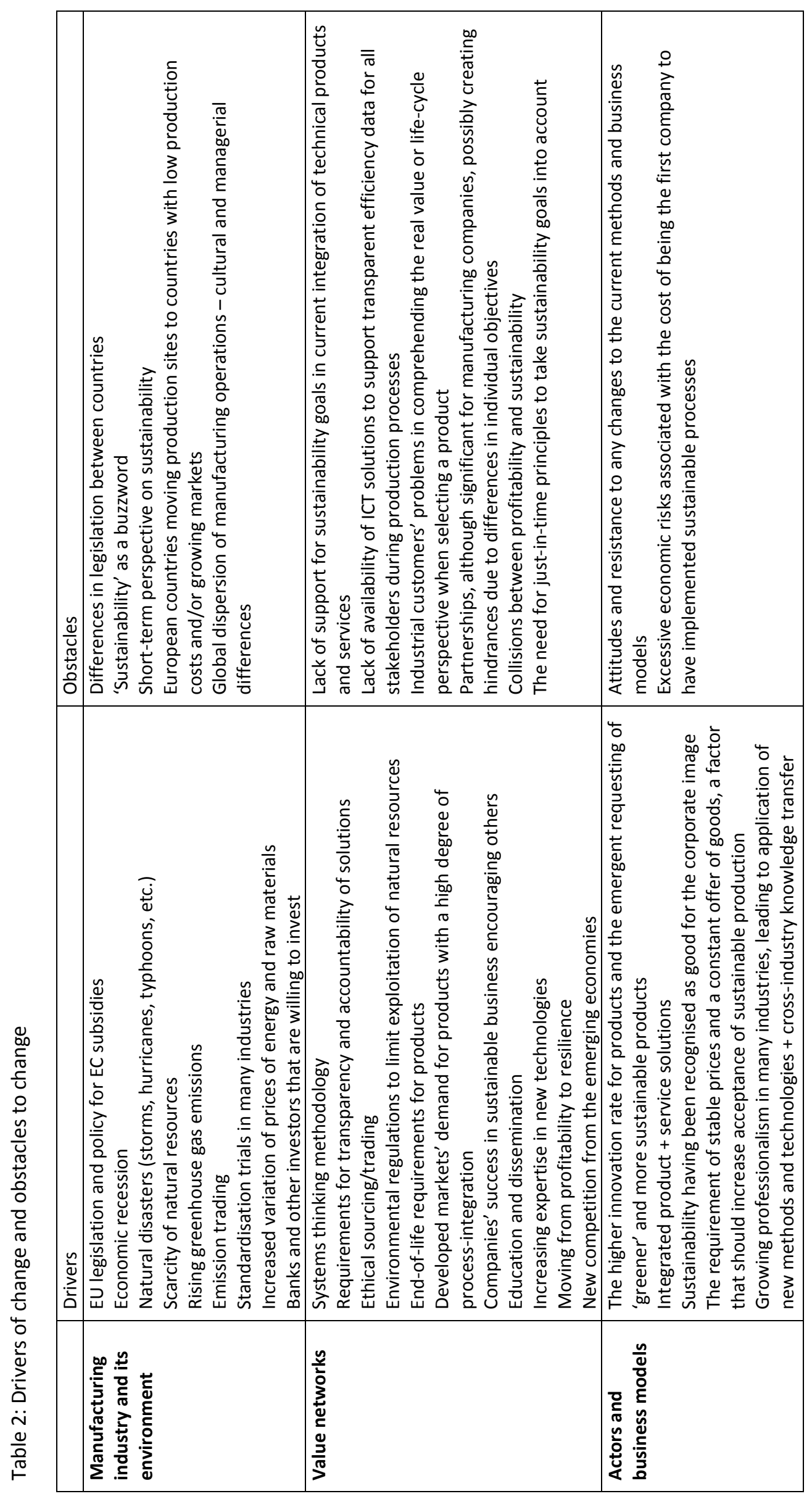


Table 3. Summary of the required changes

\begin{tabular}{|c|c|c|c|}
\hline & Short-term & Mid-term & Long term \\
\hline Macro level & & $\begin{array}{l}\text { - } \quad \text { need for propagation of } \\
\text { standards and certification and } \\
\text { hence for government-level co- } \\
\text { operation (s-r 1) }\end{array}$ & $\begin{array}{l}\text { - the behaviour and role of } \\
\text { customers, which means, for } \\
\text { example, consumers and } \\
\text { customers increasingly } \\
\text { participating in companies' } \\
\text { innovation processes (s-r } 1 \text { ) }\end{array}$ \\
\hline $\begin{array}{l}\text { Network } \\
\text { level }\end{array}$ & $\begin{array}{l}\text { efficiency in production } \\
\text { and life-cycle-orientation } \\
\text { (s-r 2) }\end{array}$ & $\begin{array}{l}\text { a new type of dynamic relation- } \\
\text { ship, horizontal collaboration } \\
\text { with partners and other } \\
\text { stakeholders (s-r 2) } \\
\text { - } \quad \text { network-level integrated key } \\
\text { performance indicators (s-r 3) }\end{array}$ & $\begin{array}{l}\text { a more systemic view of the } \\
\text { entire manufacturing network, } \\
\text { with new collaboration models } \\
\text { (s-r 2) }\end{array}$ \\
\hline $\begin{array}{l}\text { Business } \\
\text { model and } \\
\text { actor level }\end{array}$ & $\begin{array}{l}\text { the actor's willingness to } \\
\text { change and growing } \\
\text { awareness about } \\
\text { dimensions of } \\
\text { sustainability among } \\
\text { various stakeholders (s-r 1) } \\
\text { changes related to } \\
\text { sustainability in both } \\
\text { business models and } \\
\text { people (s-r 3) }\end{array}$ & $\begin{array}{l}\text { - } \quad \text { technological development is } \\
\text { essential for achieving } \\
\text { significant changes in eco- } \\
\text { efficiency (s-r 2) }\end{array}$ & $\begin{array}{l}\text { - } \quad \text { integrated models of } \\
\text { sustainability (actor ability to } \\
\text { compare settings of different } \\
\text { kinds and also balance the three } \\
\text { aspects of sustainability) (s-r 3) }\end{array}$ \\
\hline
\end{tabular}

